\title{
Metabolic implications of GH treatment in small for gestational age
}

\author{
E M Delemarre, J Rotteveel ${ }^{1}$ and H A Delemarre-van de Waal ${ }^{1}$ \\ Medical School Leiden University Medical Center, VU University Medical Center, PO Box 7057, 1007 MB Amsterdam, The Netherlands and ${ }^{1}$ Department \\ of Pediatric Endocrinology and Institute of Clinical and Experimental Neurosciences, VU University Medical Center, PO Box 7057, 1007 Amsterdam, The \\ Netherlands \\ (Correspondence should be addressed to H A Delemarre-van de Waal; Email: h.delemarre@vumc.nl)
}

\begin{abstract}
Fetal growth retardation is associated with decreased postnatal growth, resulting in a lower adult height. In addition, a low birth weight is associated with an increased risk of developing diseases during adulthood, such as insulin resistance, type 2 diabetes mellitus, hypertension, dyslipidemia, and cardiovascular diseases. Children with persistent postnatal growth retardation, i.e., incomplete catchup growth, can be treated with human GH. The GH/IGF-I axis is involved in the regulation of carbohydrate and lipid metabolism. The question of whether treatment with GH in children born small for gestational age (SGA) has long-term implications with respect to glucose/insulin and lipid metabolism has not been answered yet. In this article, the available data are reviewed.
\end{abstract}

European Journal of Endocrinology 157 S47-S50

\section{Introduction}

Growth hormone (GH) is known to have metabolic effects. It antagonizes insulin effects by increasing hepatic gluconeogenesis and glycogenolysis, thereby decreasing peripheral glucose consumption. These effects also attribute to the lipolytic effects of $\mathrm{GH}(1)$ ).

Acute GH administration elicits a decrease of the glucose uptake in muscles and glucose oxidation, while lipid oxidation increases, resulting in an increase of the blood levels of free fatty acid $(2,3)$. The lipolytic effect of $\mathrm{GH}$ depends on the fat localization. The highest lipolytic effect is exerted at the abdominal fat tissue. This explains the increased amount of abdominal fat deposits in patients with a GH deficiency.

In turn, disturbances of the carbohydrate metabolism can also modulate the secretion of GH. Patients with type 1 diabetes mellitus display a $\mathrm{GH}$ profile characterized by increased $\mathrm{GH}$ baseline levels, increased $\mathrm{GH}$ pulse amplitude, and by a decreased GH pulse periodicity (4). The high GH pulse amplitude in patients with type 1 diabetes is thought to be related to changes in insulin sensitivity, while the high GH baseline levels are associated with increased lipolysis and ketogenesis (5). In adults after prolonged fasting and in children with malnutrition, a similar increase of the $\mathrm{GH}$ secretion is observed, which may be mediated by a

This paper was presented at the Ipsen symposium, 'The evolving biology of growth and metabolism', Lisbon, Portugal, 16-18 March 2007. Ipsen has supported the publication of these proceedings. hypoinsulinemic state $(6,7)$. The increased $\mathrm{GH}$ release induces lipolysis, which in malnourished children may be the metabolic adaptation to achieve energy in order to survive.

Adults with either GH deficiency (GHD) or acromegaly with a $\mathrm{GH}$ overproduction reveal insulin resistance that develops due to increased lipolysis as the result of exposure to high amounts of GH. Visceral fat deposition is decreased in these patients (8). In contrast, patients with GHD will eventually develop insulin resistance as a result of increased visceral fat deposition (9).

Insulin-like growth factor-I (IGF-I), named as a result of its effects as an insulin sensitizer, is produced and secreted in the liver as well as in many organs. GH plays a major role in the regulation of the production and release of IGF-I in the liver. The IGF-I peptide has a structure similar to those of proinsulin and insulin molecules.

In contrast to the insulin antagonist effects of $\mathrm{GH}$, IGF-I induces hypoglycemia by the suppression of the hepatic glucose production and stimulation of the peripheral glucose uptake. Whether IGF-I can influence lipid metabolism is not clear. Recently, Simpson et al. (10) described no direct effect on lipolysis, while the IGFI challenge did reduce the hepatic glucose production and increased the peripheral glucose uptake.

The IGF-I half-life is only 10-12 min. By binding to carrier proteins, the IGFBPs family, bioavailability and bioactivity of IGF-I are extended. The levels of IGFBP-3 and IGFBP-1 are regulated by $\mathrm{GH}$ and insulin respectively (11). In turn, the numbers of $\mathrm{GH}$ receptors 
and the post-receptor signaling, responsible for IGF-I and IGFI binding protein-3 (IGFBP3) production, are also insulin dependent.

The important role of insulin in the GH/IGF-I axis makes the axis vulnerable for nutritional variations. During a hypoinsulinemic state of acute fasting, IGF-I and IGFBP1 levels will decrease. In the longer term, due to the feedback mechanism, the low IGF-I levels initiate an increase of GH in order to restore IGF-I levels. These high GH levels induce lipolysis and ketogenesis. When the fat depots are completely exhausted, GH release will drop into a complete hyposomatotropic state (7).

In conclusion, $\mathrm{GH}$ has insulin antagonist effects on the glucose metabolism in combination with a lipolytic effect, especially at the level of abdominal fat depots. In contrast, IGF-I has a strong insulin-like activity on glucose metabolism, while there is no direct effect of IGF-I on lipid metabolism.

Although IGF-I and GH have antagonistic effects with respect to insulin activity, both the primary IGF-I deficiency and the GHD syndrome are associated with insulin resistance.

\section{Metabolic consequences of being born small for gestational age (SGA)}

Intrauterine growth retardation or fetal growth retardation are the terms usually applied to fetuses with a lower birth weight than expected for gestational age. In general practice, infants with reduced size at birth are described as being born SGA. There are many definitions of being born SGA with cut-offs at the tenth centile, third centile, or below 2 s.D. from the mean after adjustment of gestational age and gender. In addition, one may distinguish small for weight, for length, or for both weight and length. Recently, a consensus statement on the definition and management of children born SGA has been published (12).

Subjects, born SGA have an increased higher risk for developing diseases in later life, such as type 2 diabetes, hypertension, dyslipidemia, and coronary heart diseases, whereby a metabolic problem may be the underlying mechanism (13).

As a group, children born SGA display decreased postnatal growth leading to decreased adult stature. Most of them will catch up in height and weight during the first years of life. However, in a small percentage catch-up growth is lacking or incomplete. The mean IGF-I and IGFBP 3 levels of these children are somewhat reduced (14).

Already at the age of 1 year, Soto and co-workers (15) observed differences in insulin sensitivity and secretion in SGA infants when compared with appropriate for gestational age (AGA) controls. In a prospective study, the authors found at the age of 1 year an increased fasting insulin level in SGA children with catch-up growth of either weight or height when compared with
SGA without catch-up growth and control AGA infants. During oral glucose tolerance tests (OGTT), the postload insulin secretion was related to the increase of height, with a higher release in children with catch-up growth. The total SGA group displayed a tendency to higher triglyceride levels.

Most studies on $\beta$-cell capacity and insulin sensitivity use OGTTs with calculations on the increase in glucose and insulin levels, or on basal levels using the HOMA and QUICKI calculations $(16,17)$. However, the hyperglycemic clamp is still the gold standard for estimating insulin sensitivity as well as $\beta$-cell capacity $(18,19)$.

In a study on insulin sensitivity in 8-year-old children born SGA at term, using the hyperinsulinemiceuglycemic clamp, Veening et al. (20) found that insulin sensitivity in SGA children was significantly lower when compared with a control AGA group. The degree of insulin resistance was related to body mass index (BMI); children with a BMI below $17 \mathrm{~kg} / \mathrm{m}^{2}$ had similar insulin sensitivities as the AGA group, while a higher BMI was associated with decreased insulin sensitivity. In addition, catch-up in height tended to be related with decreased insulin sensitivity.

Besides evidence for disturbances in carbohydrate and lipid metabolism, many studies in SGA children describe increased systolic blood pressure already during childhood (21). The increase is related to acceleration of postnatal growth. Although the differences are small, an increase of $2 \mathrm{mmHg} / \mathrm{kg}$ birth weight, it may have an important impact on health at the long term, especially in the presence of metabolic problems related to low birth weight.

From human and animal studies, it is known that fetal malnutrition interferes with the development of the pancreas $(22,23)$. SGA children have fewer $\beta$-cells, which may explain the increased risk to type 2 diabetes, as a result of insulin resistance (22). However, the only study in children born SGA examining insulin secretion showed no defect in insulin secretion (24).

In conclusion, children born SGA have an increased risk to develop cardiovascular risk factors, such as insulin resistance and hypertension in later life. There is evidence that the short and thin children, although born SGA, may be less at risk for these factors.

\section{GH treatment in short children born SGA}

Born SGA and incomplete or lack of postnatal catch-up growth at the age of 4 years is an indication to treat with GH (25). Many studies of GH treatment in short SGA children have now been performed. Studies till final height show that GH treatment is effective to increase adult stature.

Previous studies in patients with Turner syndrome, also a non-GH-deficient indication for GH treatment, reported a reversible insulin insensitivity during GH treatment (26). In children born SGA, the treatment 
with $\mathrm{GH}$ results in a reduction of insulin sensitivity as well (27). During OGTT, higher fasting insulin and glucose stimulated insulin levels can be observed, which are increasingly elevated with a higher GH dose. Although the glucose and HbA1c levels show a slight increase, they remain in the normal range (27). Similar increases in glucose and insulin levels are seen in large groups of SGA children on GH treatment as described in the US trial and KIGS study (28).

Recently, data have been published on carbohydrate metabolism in adults treated with $\mathrm{GH}$, several years after discontinuation of GH. These data show that in patients treated for a mean period of 7.3 years with $\mathrm{GH}$, the carbohydrate metabolic status 6.5 years after $\mathrm{GH}$ discontinuation is comparable with untreated young adults born SGA (29). However, this study did not use the hyperinsulinemic-euglycemic clamp technique, which may be necessary to find differences in insulin sensitivity during young adulthood.

The question is still whether the long-term hyperinsulinemia as observed during GH treatment can have effects in later life. The only conclusion we can draw from the available data is that after $\mathrm{GH}$ treatment, the carbohydrate metabolism in the GH-treated SGA adult may be similar to the untreated SGA adult. However, during infancy and childhood short SGA children have a favorable metabolic profile. This favorable metabolic profile may turn unfavorable when the child is treated with $\mathrm{GH}$ for its short stature. The advantage of gaining height should be balanced against the possible disadvantage of metabolic damage whenever $\mathrm{GH}$ therapy is considered in a short child born with a low birth weight.

\section{Disclosure}

This paper forms part of a European Journal of Endocrinology supplement, supported by Ipsen. The authors disclose: neither HA Delemarre-van de Waal, J Rotteveel or E Delemarre has a conflict of interest. This article was subject to rigorous peer review before acceptance and publication.

\section{References}

1 Randle PJ, Garland PB, Hales CN \& Newsholme EA. The glucose fatty-acid cycle. Its role in insulin sensitivity and the metabolic disturbances of diabetes mellitus. Lancet 19631 785-789.

2 Möller N, Jörgensen JO, Schmitz O, Möller J, Christiansen J, Alberti KG \& Orskov H. Effects of a growth hormone pulse on total and forearm substrate fluxes in humans. American Journal of Physiology 1990258 E86-E91.

3 Moller N, Schmitz O, Porksen N, Moller J \& Jorgensen JO. Doseresponse studies on the metabolic effects of a growth hormone pulse in humans. Metabolism 199241 172-175.

4 Pal BR, Matthews DR, Edge JA, Mullis PE, Hindmarsh PC \& Dunger DB. The frequency and amplitude of growth hormone secretory episodes as determined by deconvolution analysis are increased in adolescents with insulin dependent diabetes mellitus and are unaffected by short-term euglycaemia. Clinical Endocrinology 199338 93-100.

5 Pal BR, Phillips PE, Matthews DR \& Dunger DB. Contrasting metabolic effects of continuous and pulsatile growth hormone administration in young adults with type 1 (insulin-dependent) diabetes mellitus. Diabetologia 199235 542-549.

6 Ho KY, Veldhuis JD, Johnson ML, Furlanetto R, Evans WS, Alberti KG \& Thorner MO. Fasting enhances growth hormone secretion and amplifies the complex rhythms of growth hormone secretion in man. Journal of Clinical Investigation $1988 \mathbf{8 1}$ 968-975.

7 Pimstone B. Endocrine function in protein-calorie malnutrition. Clinical Endocrinology 19765 79-95.

8 Angeletti G. The metabolic complications of acromegaly. Journal of Endocrinology Investigation 200326 18-19.

9 Beshyah SA, Henderson A, Niththyananthan R, Skinner E, Anyaoku V, Richmond W, Sharp P \& Johnston DG. The effects of short and long-term growth hormone replacement therapy in hypopituitary adults on lipid metabolism and carbohydrate tolerance. Journal of Clinical Endocrinology and Metabolism 1995 80 356-363.

10 Simpson HL, Jackson NC, Shojaee-Moradie F, Jones RH, RussellJones DL, Sönksen PH, Dunger DB \& Umpleby AM. Insulin-like growth factor I has a direct effect on glucose and protein metabolism, but no effect on lipid metabolism in type 1 diabetes. Journal of Clinical Endocrinology and Metabolism 200489 425-432.

11 Hwa V, Oh Y \& Rosenfeld RG. The insulin-like growth factorbinding protein (IGFBP) superfamily. Endocrine Reviews 199920 761-787.

12 Clayton PE, Cianfarani S, Czernichow P, Johannsson G, Rapaport R \& Rogol A. Management of the child born small for gestational age through to adulthood: A Consensus Statement of the International Societies of Pediatric Endocrinology and the Growth Hormone Research Society. Journal of Clinical Endocrinology and Metabolism 200792 804-810.

13 Barker DJ. The developmental origins of chronic adult disease. Acta Paediatrica 200493 26-33.

14 Tenhola S, Halonen P, Jaaskelainen J \& Voutilainen R. Serum markers of $\mathrm{GH}$ and insulin action in 12-year-old children born small for gestational age. European Journal of Endocrinology 2005 $152335-340$.

15 Soto N, Bazaes RA, Pena V, Salazar T, Avila A, Iñiguez G, Ong KK, Dunger DB \& Mericq MV. Insulin sensitivity and secretion are related to catch-up growth in small-for-gestational-age infants at age 1 year: results from a prospective cohort. Journal of Clinical Endocrinology and Metabolism $2003 \mathbf{8 8} 3645-3650$.

16 Matthews DR, Hosker JP, Rudenski AS, Naylor BA, Treacher DF \& Turner RC. Homeostasis model assessment: insulin resistance and $\beta$-cell function from fasting plasma glucose and insulin concentrations in man. Diabetologia $1985 \mathbf{2 8} 412-419$.

17 Katz A, Nambi SS, Mather K, Baron AD, Follmann DA, Sullivan G \& Quon MJ. Quantitative insulin sensitivity check index: a simple, accurate method for assessing insulin sensitivity in humans. Journal of Clinical Endocrinology and Metabolism $2000 \mathbf{8 5}$ 2402-2410.

18 DeFronzo RA, Tobin JD \& Andres R. Glucose clamp technique: a method for quantifying insulin secretion and resistance. American Journal of Physiology 1979237 E214-E223.

19 Efendic S, Cerasi E \& Luft R. Role of glucose in arginine-induced insulin release in man. Metabolism 197120 568-579.

20 Veening MA, van Weissenbruch MM \& Delemarre-van de Waal HA. Glucose tolerance, insulin sensitivity, and insulin secretion in children born small for gestational age. Journal of Clinical Endocrinology and Metabolism 200287 4657-4661.

21 Huxley RR, Shiell AW \& Law CM. The role of size at birth and postnatal catch-up growth in determining systolic blood pressure: a systematic review of the literature. Journal of Hypertension 2000 18 815-831.

22 van Assche FA \& Aerts L. The fetal endocrine pancreas. Contributions in Gynecology and Obstetrics $1979544-57$. 
23 Garofano A, Czernichow P \& Breant B. Beta-cell mass and proliferation following late fetal and early postnatal malnutrition in the rat. Diabetologia $1998 \mathbf{4 1} 1114-1120$.

24 Veening MA, van Weissenbruch MM, Heine RJ \& Delemarre-van de Waal HA. Beta-cell capacity and insulin sensitivity in prepubertal children born small for gestational age: influence of body size during childhood. Diabetes 200352 1756-1760.

25 Clayton PE, Cianfarani S, Czernichow P, Johannsson G, Rapaport R \& Rogol A. Management of the child born small for gestational age through to adulthood: A Consensus Statement of the International Societies of Pediatric Endocrinology and the Growth Hormone Research Society. Journal of Clinical Endocrinology and Metabolism 200792 804-810.

26 Sas T, Muinck Keizer-Schrama S, Aanstoot HJ, Stijnen T \& Drop S. Carbohydrate metabolism during growth hormone treatment and after discontinuation of growth hormone treatment in girls with Turner syndrome treated with once or twice daily growth hormone injections. Clinical Endocrinology $2000 \mathbf{5 2} 741-747$.
27 Sas T, Mulder P, Aanstoot HJ, Houdijk M, Jansen M, Reeser M \& Hokken-Koelega A. Carbohydrate metabolism during long-term growth hormone treatment in children with short stature born small for gestational age. Clinical Endocrinology $2001 \mathbf{5 4}$ 243-251.

28 Cutfield WS, Lindberg A, Rapaport R, Wajnrajch MP \& Saenger P. Safety of growth hormone treatment in children born small for gestational age: the US trial and KIGS analysis. Hormone Research $200665153-159$.

29 van Dijk M, Bannink EM, van Pareren YK, Mulder PG \& HokkenKoelega AC. Risk factors for diabetes mellitus type 2 and metabolic syndrome are comparable for previously growth hormone-treated young adults born small for gestational age (sga) and untreated short SGA controls. Journal of Clinical Endocrinology and Metabolism 200792 160-165.

Received 15 March 2007

Accepted 2 May 2007 